\title{
Factors Affecting Nurses' Experiences Related to Current Handover Process between Emergency Department and In-patient Units
}

\author{
Shereen R. Dorgahm ${ }^{1}$, and Heba K. Obied ${ }^{2}$
}

\author{
1 Assistant professor of nursing Administration Faculty of Nursing, Tanta University, \\ Tanta, Egypt \& Imam Abdulrahman Bin Faisal University, College of Nursing, Nursing \\ Education Department. \\ ${ }^{2}$ Assistant Professor of Nursing Administration, Faculty of Nursing, Tanta University.
}

\begin{abstract}
:
Handover process is fundamental and crucial component of patient safety care. Communication failure constitutes a major source of medical mistakes or sentinel events. So the study aimed to assess factors affecting nurses' experiences related to current handover process between emergency department and in-patient units.A cross- section, correlational design was used. The study was conducted at Tanta University Emergency Hospital, (60) nurses were included. One Structured Questionnaire was used; including three parts Nursing Satisfaction with Handover, Current Handover Process Quality, and Information Inventory Provided in Current Handover Process. (33.3\%) of the nurses reported they rarely had opportunity to ask questions and to clarify information during handover process. (77\%) of them were dissatisfied with the current handover process. (30\%) reported they experienced error during handover process due to ineffective communication. (45\% and $31 \%$ ) of the nurses viewed that providing accurate and honest information and availability of structured standardized process is important to improve handover process. $49.9 \%$ of the nurses viewed they did not provide total information during handover process So, we recommended establishing standardized tools according to ED context and each inpatient unit to optimize the quality of handover process, and conduct training programs to enhance nurses' satisfaction by helping them to gain knowledge and apply tools to manage the intricate nature of handover process.
\end{abstract}

Key Words: Emergency Department, Handover, In-patient Unit. 


\section{Introduction}

Nurses from the Emergency Department (ED) are responsible for reporting a handover to the floor unit when a patient is admitted to the unit. The handover process is a ritual that is strongly integrated in the nursing customs and culture. Handover is described as a critical instrument in transferring care services from one nurse to another to keep all nursing team on one page and to ensure continuity of patient care. ${ }^{(1)}$ Although accurate, meaningful and up-to-date data regarding the patient's care is one of the primary purposes in nursing handovers, clinical handovers play other significant roles, emotional, educational and social. Other tasks include promoting the team build-up and socialization of newly appointed nurses, as well as detecting mistake. ${ }^{(2)}$

There are various kinds of handovers, such as handovers between specialties (inter- or intra-hospitals), handovers through admission or discharge and handovers between shifts on the same unit (change of shift handover). It also occurs when assigned nurse leave the unit for short time and when assignments changed. During the handovers, specific technology can also be used including audio recorders, pagers, handheld devices or Electronic Medical Record (EMR), faxed or given verbally by phone or in individual by the healthcare professional. Handover can take place in nursing station, conference room, or even at patient bedside that is viewed as the best place where recipient nurse has opportunity to assess patients' general condition. ${ }^{(3,4)}$

Handovers occur in a multitude of environments and situations.It is carried out during times of transition, when nurses discuss the data for patients and plan the next steps for the care of the patient. This transition time often includes entry, therapy and discharge. In many instances, the floor units are given bad fulfillment owing to a number of factors. Those are the reasons why the healthcare professional offering the handover variations in profession, linguistic, interaction and the expectations are different. These results allow the handover between the Emergency Department and the floor units to be improved. ${ }^{(5,6)}$

There is increasing awareness that the provision of safe and efficient patient care is critically related to high-quality handover. Around twenty percent up to thirty percent of data transferred during handover updates are not documented by the medical record. The effects of less than optimal handover include negative events, 
medical diagnostic and therapy delays, redundant communication, and more as redundant operations such as extra procedures, testing, reduced providerpatient satisfaction, greater expenses, longer hospital stays, increased hospital admission and reduced efficient health care provider training have proven to be extremely variable in quality and composition. With a dramatic increase in patient handover activity, it is astonishing that standardized, reliable measurement tools remain intangible. ${ }^{(7)}$

Effective handover strategies across varied healthcare environments are difficult to create and implement. The clinical handover is a complicated procedure, and various factors can affect it. Firstly, physical barriers, including noisy environments, such as telephone or calling lights, as well as emotional and physical stress may prevent the handover from occurring and may minimize the chance of asking and answering questions. (8, 9) Secondly, the absence of support infrastructure, work overload and differences in the cultural unit or department have become important obstacles to enhancing the handover process. ${ }^{(9)}$ Finally, the handover method could also interfere with the healthcare providers' interpersonal communication abilities, their understanding and experience. ${ }^{(9,10)}$

The method of handover communication is an important part of patient care and a key element for patient safety. The effects on safety have been well documented from the ineffective handover. Handover communications deficiencies are frequent and constitute a significant source of errors or sentinel occurrences. (11) 489 (64\%) instances were ascribed to communication failures out of 764 sentinel instances reviewed in 2014 by the Joint Commission. Ten years ago the Joint Commission proposed the 2006 National Patient Safety Goal which required "a standardized approach to handover communication" to improve patient handovers and reduce side effects related to medical errors. ${ }^{(11)}$

\section{Significance of the study}

The emergency department and in-patient unit handovers got comparatively little attention, though it is complicated and carries greater hazards in terms of overcrowding in ED, patient care methods and the absence of proven interactions between health professionals of the same area than handovers between providers of the same specialty. The transfer from ED to the hospital unit generally occurs where 
the patient is most susceptible because his clinical course is not clear, medical care is just in progress and laboratory findings continue to be in progress. ${ }^{(\mathbf{8 , 1 2})}$ Literature displayed that much is written about how cross-shift handovers between healthcare personnel in the same department happen during shift changes. However, very few studies have been performed regarding transfers from EDs and other units between nurses. ${ }^{(13)}$

Although ineffective communication at transitional points have been recognized as the most frequent cause of error in inpatient and the main source of disaster or sentinel incidents. However, there is very restricted literature on best practice based on evidence, particularly with regard to EDs for hospitalization. In order to assess distinct methods, nurses' satisfaction was carried out to demonstrate their opinions related to the existing handover process and appropriate procedures of specific clinical context engaged in the patient inter unit handover. ${ }^{(10,14,15)}$

The Institute of Medicine (IOM) has noted, however, that "in insufficient handovers security often fails first". It is a question of the impacts of ineffective handovers: negative events and risk to health of patients. Various studies have shown that transfer is vulnerable to patient safety and provides additional reasons to invest in handover training for health professionals. ${ }^{(8,16)}$ The current study aimed to explore nurses' experiences with current handover process, identify possible factors that affect the quality of handover process during inter-unit transfer and suggested possible techniques to improve the quality handover process.

\section{Methodology}

Aim:

The present study aimed to assess factors affecting nurses' experiences related to current handover process between emergency department and in-patient units.

\section{Research Questions:}

1. What are the nurses' experiences regarding current handover process?

2. Are nurses satisfied with the current handover process between ED and in-

patient units?

3. What are nurses' suggestions to improve the quality of current handover process?

4. Is there a correlation between nurses' experiencing errors and the quality level of handover process?

5. Is there a correlation between information provided during handover and quality level of handover process? 


\section{Design:}

A cross-sectional, correlational design was used in the present study to describe different factors which affect the quality of current Handover process and type of data provided and experiencing errors due to ineffective communication during Handover. It is a scientific method which involves describing the relationship among variables without influencing it at any way. $^{(17)}$

\section{Setting:}

The study was conducted at Tanta University Emergency Hospital, including Emergency Department (ED), Medical Unit and, Operating Room (OR).

\section{Subject:}

Convenient sample included all (60) nurses were available at the time of data collection who conducted or participated in handover process, 20 nurses from total (57 nurses) working in Emergency Department, 23 nurses from total (65 nurses) working in Medical Unit, and 17 nurses from total (48 nurses) working in Operating Room at the time of data collection.

\section{Tool:}

One tool was utilized to collect the data from the study sample. It was translated and modified by the researchers; it included three sections as the following:
First section: Nurses' Satisfaction with Handover Structured Questionnaire where the researchers added personal data; encompassed three parts; (I) nurses' personal data including age, marital status, working unit, and level of education. (II) Nurses Satisfaction with Current Handover, included 3 closed end questions about; type of process currently used scored as (written=3, SBAR=2, no tool=1), opportunity to ask questions and clarify information scored as (always $=3$, sometimes $=2, \quad$ never $=1)$; nurses' satisfaction with current handover process scored as (satisfied $=2$, dissatisfied $=1$ ). This part was used to assess nurses' satisfaction with handover. (III) It was used to get nurses' opinions to improve current handover process; included three open end questions about experiencing error during handover process due to ineffective communication, factors affecting quality of current handover, and type of handover report preferred (Marutyan, 2016). ${ }^{(8)}$

Second section: Current Handover Process Quality Questionnaire; used to assess the quality of current handover process. This tool was modified to

meet the demand of inter-unit handover assessment by Delrue (Delrue, 2013) ${ }^{(18)}$. It was modified by the researchers through 
changing the subscales of quality to; conduction of handover process (5 items), teamwork (4 items), documentation (4 items), and surroundings of handover (3 items). Scoring system: nurses' responses measured was modified from 4-points to three points Likert Scale agree (3), uncertain (2), and disagree (1). ${ }^{(8)}$ For each subscale, the subtotal score was determined separately according to the number of items. The total scale score ranged from 16-48. The levels of total quality score determined by the researchers accordingly; high level $\geq 80 \%$ scored (48$38.4)$, moderate level $<80 \%$ - $60 \%$. scored $(38.3-28.8)$ and low level $<60 \%$ scored (28.7-16).

- Last section: Information Inventory Provided in Current Handover Process Questionnaire. Was modified to be selfadministered questionnaire instead of an observational checklist related to the information that provided in current handover process, classified into patient identification information (10 items), patient history (5 items), assessment (5 items), medications, laboratory investigation and patient imaging (4 items), medical devices attached to patient (4 items), and doctor orders (2 items). Scoring system utilized two points Likert Scale yes (1) and no (0). ${ }^{(8)}$ The total scores were calculated by summing all scale's items of participants.

\section{Method}

\section{Data Collection}

The data was collected through a selfadministered questionnaire; it took approximately 20 to 30 minutes for each participant when they have some downtime to respond to questions. The data were collected within one month December 2018.

The tool was introduced to a jury of 5 experts to test its face and content validity. A pilot study was conducted on $6(10 \%)$ of $\mathrm{ED}, \mathrm{OR}$ and medical nurses to assess the tool's applicability and reliability "the pilot was not included in the study subject". Also the tool was tested two times for its reliability (test-retest reliability) with two separate weeks to ensure that the questionnaire was applicable and respondents ' answers consistency. The value of Cronbach's alpha test coefficient was 0.82 and the Content Validity Index was $90 \%$.

\section{Ethical Considerations}

After the approval of the director of Tanta University Emergency Hospital, the purpose of the study was explained to the participant nurses and their consents were obtained. They were ensured about the confidentiality of their data, and the right 
to withdraw was confirmed. The data was collected within one month December 2018. The researchers met the participants in their workplace and distribute the questionnaires according work load in the unit.

\section{Statistical analysis}

The study data was collected, tabulated and subjected to statistical analysis by SPSS (version 17), also Microsoft office Excel was used for data handling and graphical presentation. Quantitative variables are described by the mean, and Standard Deviation (SD). Qualitative categorical variables are described by proportions and percentages.

\section{Results:}

Table (1) shows nurses' personal characteristic data.High percent $(73.3 \%)$ of participant nurses fall in the age group between 20 up to less than or equal 40 years with mean age $33.918+8.88$. Also $75.0 \%$ of them were married, and majority (93.3\%) of them had Bachelor Degree. Around one thirds of the nurses $(38.3 \%$ and $33.3 \%$ ) were working in medical unit and emergency room respectively.

Fig (1) shows type of tool currently used in handover process. High percent $(70 \%)$ of the nurses reported they use written template in handover process, while one fifth $(20 \%)$ reported they did not use any tool during handover process.

Fig (2) shows the opportunity to ask questions and clarify information during handover. Around three fifths $(58 \%)$ of the nurses reported they never had the opportunity to ask questions and to clarify information during handover process. Only less than one fifth (17\%) of the nurses reported they always had the opportunity to ask questions and clarify information during handover process.

Fig (3) shows nurses' satisfaction with the current handoverprocess in ED to inpatient. Less than one quarter $(23 \%)$ of the nurses were satisfied with the current handover process. While more than three quarters $(77 \%)$ of them were dissatisfied with the current handover process.

Fig (4) shows experiencing errors due to ineffective communication during handover process. Around one third (30\%) of the nurse reported they experienced error during handover process due to ineffective communication.

Fig (5) shows suggestions to improve the quality of current handover process. More than two fifths $(45 \%)$ of the nurses viewed that providing accurate and honest information is the key to improve current handover process. Around one third (31\%) 
of them viewed that availability of structured and standardized process is important to improve handover process. While only more than one tenth $(13 \%$ and $11 \%$ ) of them viewed that providing adequate time and number of nurses as well as training are important to improve current handover process respectively.

Fig (6) shows type of handover report preferred by nurses.High percent $(65 \%)$ of the nurses preferred written followed by more than quarter $(28.3 \%)$ preferred face to face handover.

Fig (7)shows nurses' opinion regarding levels of quality for the current handover process.Around half of nurses (48\%) viewed that the total current handover process had high quality level. More than half $(53 \%)$ of the nurses perceived documentation of current handover process as high quality. While more than half (55\%, 55\% and 53) of them viewed teamwork, surroundings, and conduction of current handover process are of moderate and low quality levels respectively.

Fig (8) shows information inventoryprovided by nurses during current handover process. Around half (49.9\%) of the nurses viewed they did not provide total information during current handover process. More than three fifths $(67.5 \%$ and $62.5 \%$ ) of them viewed they did not provide adequate information regarding doctor orders and medical devices attached to patient respectively. Around two fifths $(44.8 \%, 44.2 \%, 40.8 \%$ and $40 \%)$ of nurses perceived they did not provide adequate information of patient identification data, history, assessment, and treatment, laboratory investigation, and patient imaging respectively.

Table (2) shows correlation between nurses' experiencing errors and quality level of handover process. There was high statistical significant correlation between nurses' experiencing errors and level of handover process quality.

Table (3) shows correlation between information provided during handover and quality level of handover process. There was a statistical significant correlation between information provided during handover and total quality level of handover process. 
Table (1): Nurses' personal characteristic data. $(\mathbf{N}=60)$

\begin{tabular}{|c|c|c|c|c|c|}
\hline Items & No. & $\%$ & Items & No. & $\%$ \\
\hline Age & & & Work unit & & \\
\hline $20-\leq 40$ & 44 & $73.3 \%$ & Emergency Dep. & 20 & $33.3 \%$ \\
\hline$>40$ & 16 & $26.7 \%$ & Medical Unit & 23 & $38.3 \%$ \\
\hline Range & $(22-52)$ & & Operating Room & 17 & $28.3 \%$ \\
\hline Mean \pm SD & $33.918+8.88$ & & Educa & al lev & \\
\hline Marital status & & & Bachelor degree & 56 & $93.3 \%$ \\
\hline Married & 45 & $75.0 \%$ & Associate deoree & 4 & 67 \\
\hline Not married & 15 & $25.0 \%$ & Associate degree & 4 & 0.1 \\
\hline
\end{tabular}

Type of tool currently used in handover process

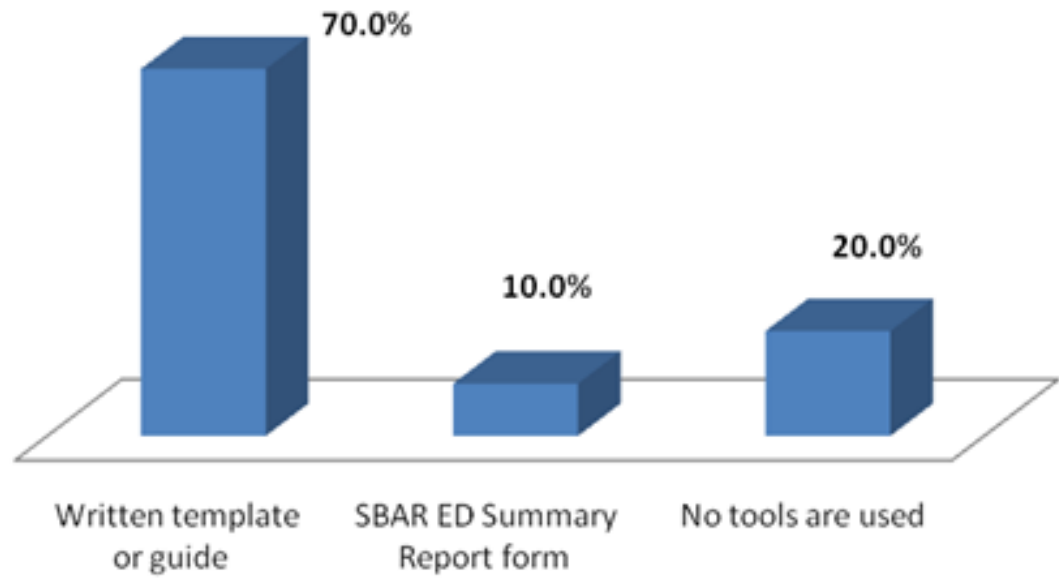

Fig.(1) the type of tool currently used in handover

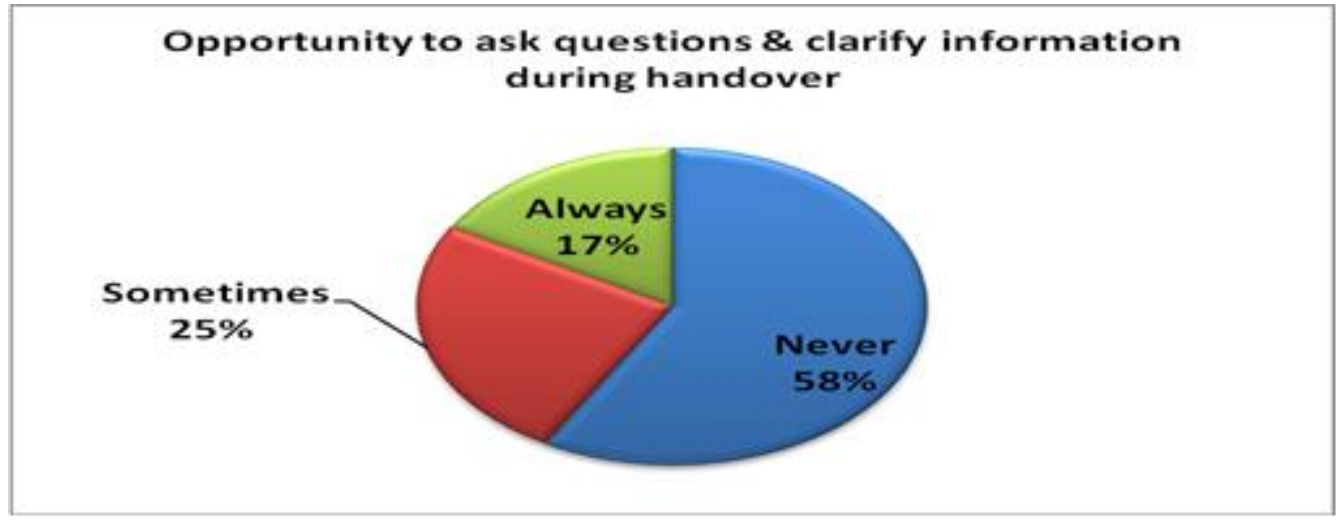

Fig. (2) The opportunity to ask questions and clarify information during handover 


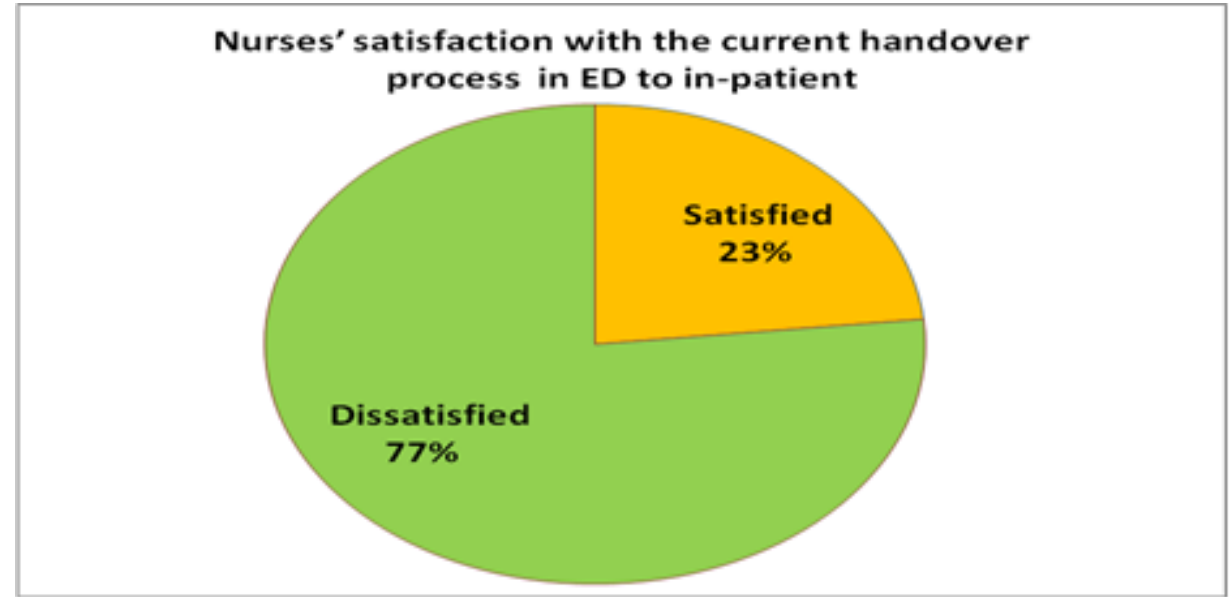

Fig. (3) Nurses' satisfaction with the current handover process in ED to in-patient

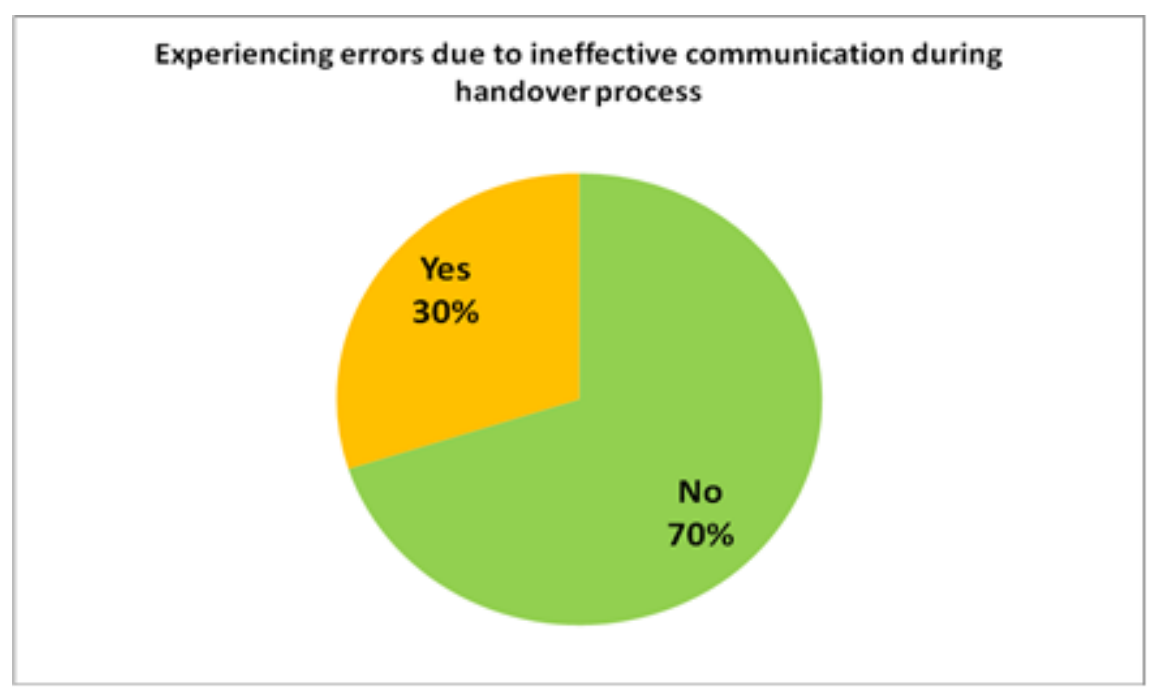

Fig. (4) Experiencing errors due to ineffective communication during handover process 


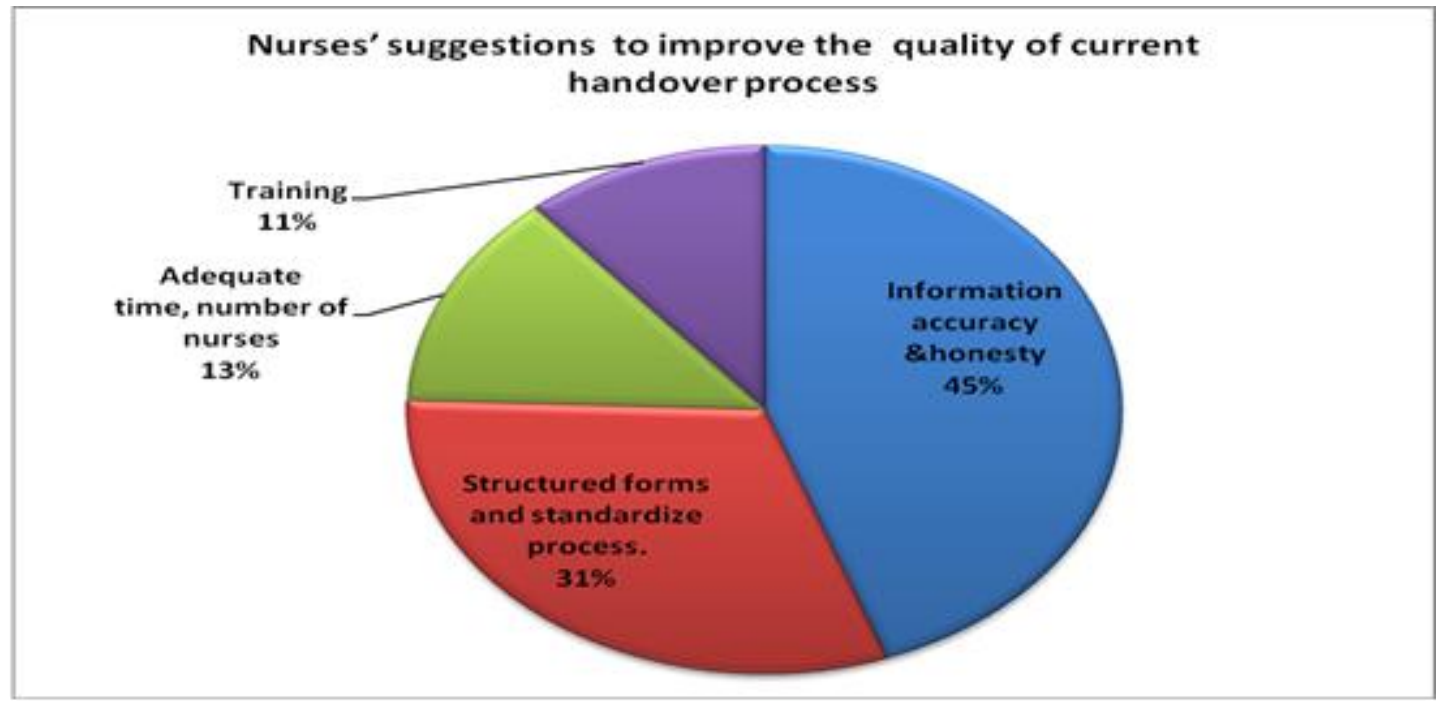

Fig. (5) Nurses' suggestions to improve the quality of current handover process

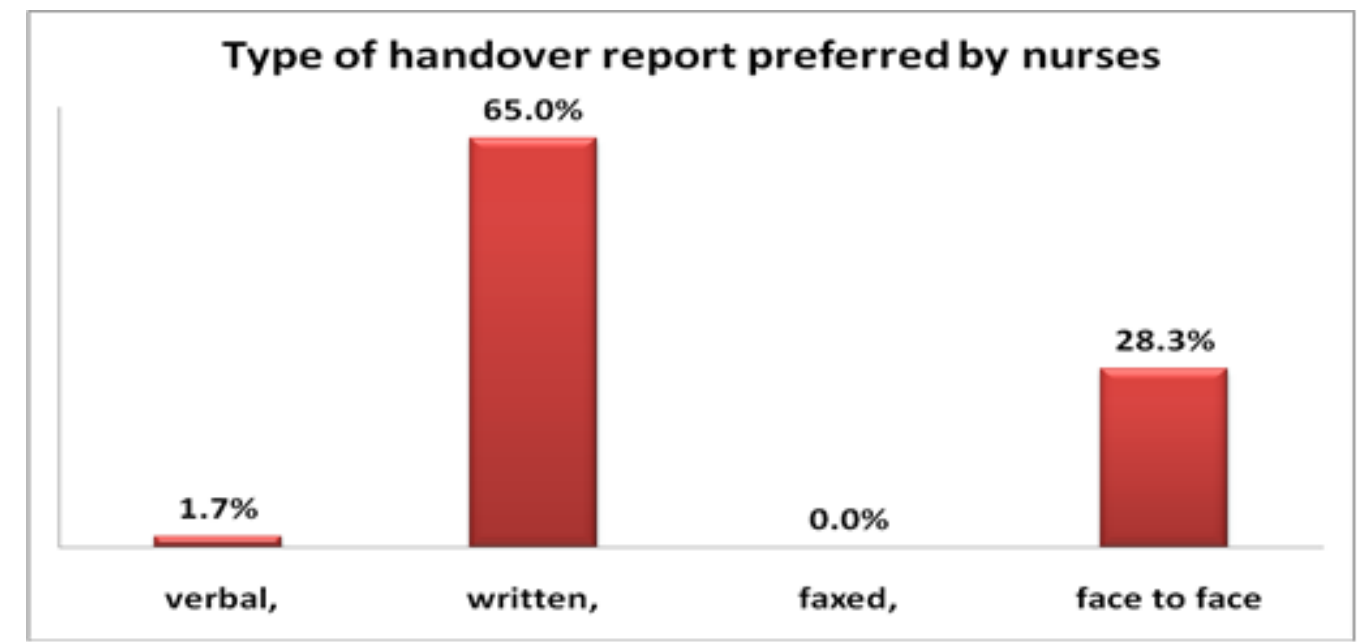

Fig. (6) Type of handover report preferred by nurses 


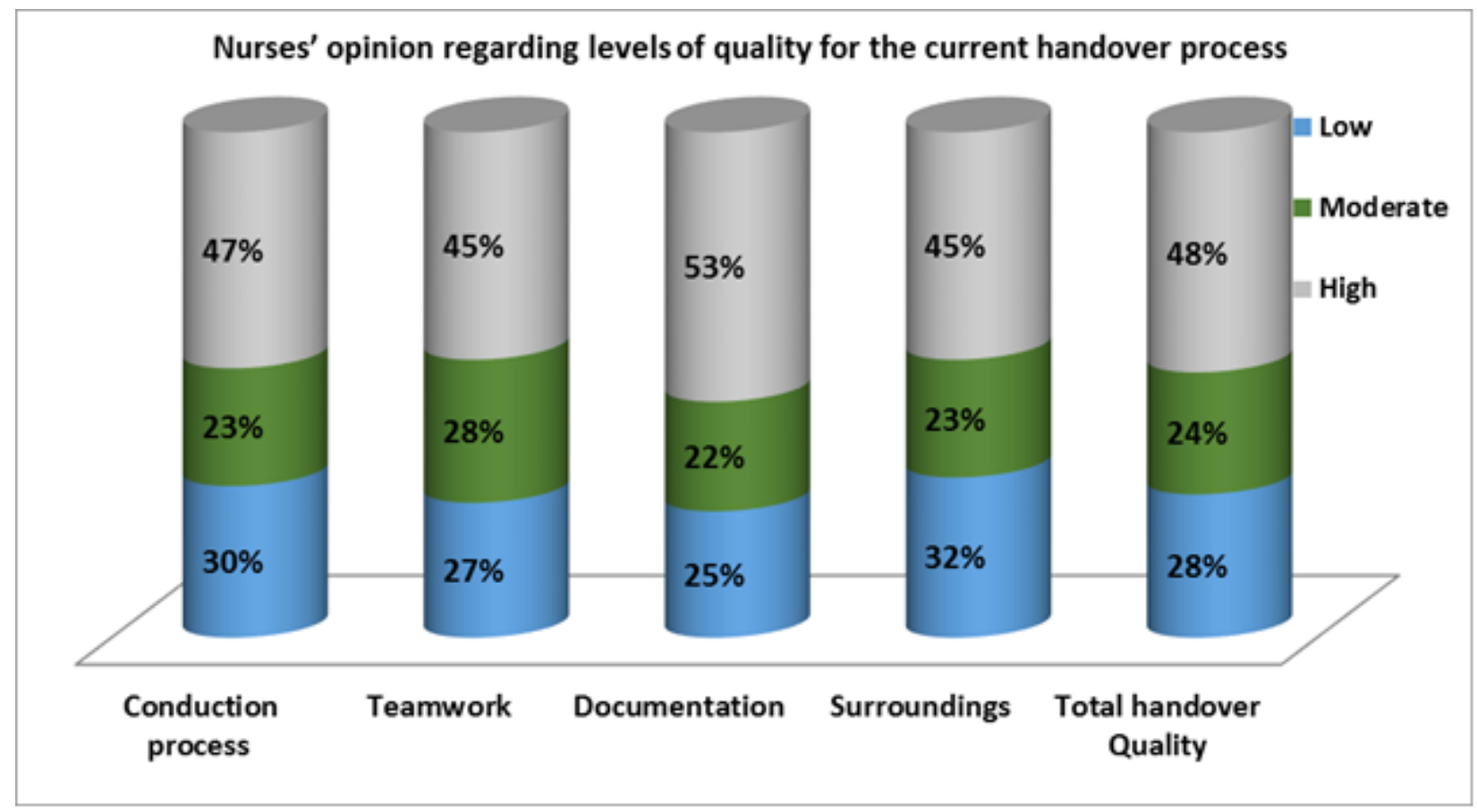

Fig (7) Nurses' opinion regardinglevels of quality for the current handover process

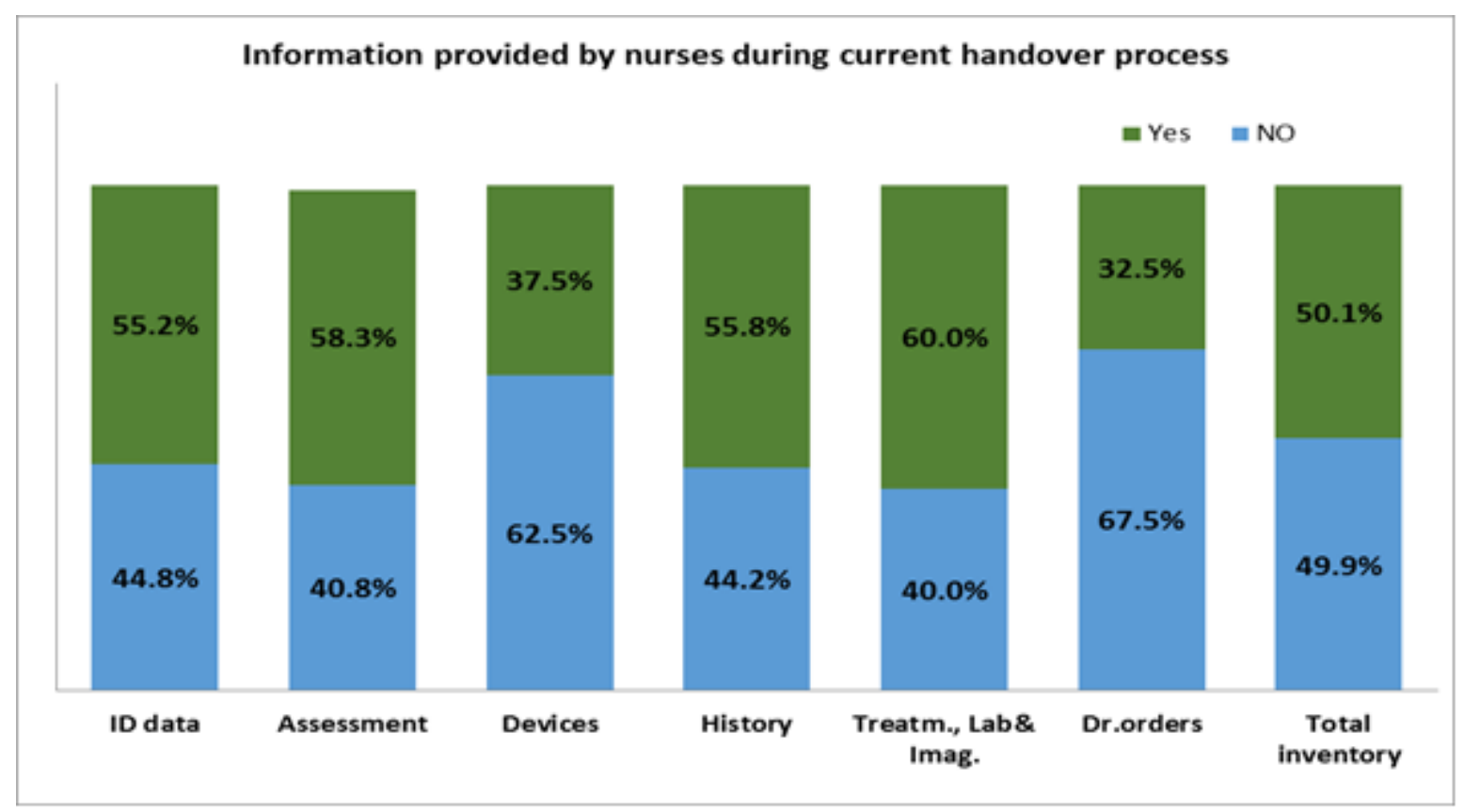

Fig (8) Information inventory provided by nurses during current handover process 
Table (2) Correlation between nurses' experiencing errors and quality level of handover process.

\begin{tabular}{|l|c|l|}
\hline Pearson Correlation Coefficient & $\mathbf{0 . 5 9}$ & Level of significance \\
\hline $\mathrm{P}$ value & 0.00000 & $\mathbf{P}<\mathbf{0 . 0 0 1}$ H S \\
\hline
\end{tabular}

Table (3) Correlation between information provided during handover and quality level of handover process

\begin{tabular}{|l|c|l|}
\hline Pearson Correlation Coefficient & $\mathbf{0 . 2 9}$ & Level of significance \\
\hline $\mathrm{P}$ value & 0.02460 & $\mathbf{P}<\mathbf{0 . 0 5}$ S \\
\hline
\end{tabular}




\section{Discussion}

Results in the current study demonstrate that high percentage of nurses preferred the using of a written template and face to face handover process. This may be due to individual mental model differences which could lead to a discrepancy between methods and information types which a provider considers to be essential to report and to receive shifts. In practice, variations create an additional vulnerability that may be exacerbated further by associated factors like memory deficiencies, overload of information, and interference (Hilligoss and Cohen, 2011) ${ }^{(19)}$. However, general information on the relative strengths and limitation of various handover techniques are inconsistent, and varies from one person to the next to the other, with writing, tape recorded and verbal face-toface (Staggers and Blaz, 2013; Carroll et al., 2012) ${ }^{(2,20)}$. While many of the oral handover contents are dictated by patients ' complexity, experience and institutional considerations, certain information should be transmitted in written form or easily accessible (digital medical recourse). These results are consistent with Jewell (2016) (21) who reported that ideally, efficient and effective handovers combine the written and verbal content of printed material (automatic medical documentation, as much as possible).

Nurses in the present study rarely had the chance during handover processes to ask questions or clarify data. This result contradictedby Rhudy et al., 2019 and Birmingham et al., $2015^{(22,23)}$ they stressed the importance of interactive dialogue during handover which offers the chance for nurses to ask and answer questions.This dialog most often occurs when nurses have mutual confidence and respect.There has also been much sharing of data, regular interruptions and restricted time to ask questions (Young et al., 2016). ${ }^{(24)}$ In handover, nurses can have different information and communication expectations with preferences for contact with the eye and the ability to ask questions or report without disruption (Tobianoet al., 2020 and Carroll et al., 2012). ${ }^{(20,25)}$

Findings of the current study show that more than three quarters of the nurses were dissatisfied with the current handover process. These findings may be due to that the data received during the handover was often poor, subjective and meaningless for nurses; the method of the handover was time consuming; and frequent interruptions affected the handover.Staggers and Blaz 
(2013) ${ }^{(2)}$ articulated the need to structure the handover techniques for the function of nurses and their corresponding needs. Studies have demonstrated that standardization is a way of creating rules, and using structured handover instruments offers the means to determine the helpful and applicable data (Drach-Zahavy et al. 2015; Nasarwanji et al, 2016). ${ }^{(26,27)}$

About a third of the nursing staff reported errors related to ineffective communication during the handover process. This result may be attributed to high workload, time limitations, various approaches to patient care and a lack of strong relationships between the care providers. This finding is in line with Briones (2016) ${ }^{(5)}$ who stated that the interruptions were predominant and varied and that information flow gaps were generated by the multi-task and adjustments which occurred within an ED. It also noted that for clinicians the nature of the communication process in the ED was difficult and cognitive. The health care team, which makes information management and data exchange critical tasks for nurses, regarded nurses as the ' center integrator of data (Keenan et al., 2013). (28) Communication among nurses however remains inefficient and despite the routine clinical practice of reporting or receiving, handover continues to be a main cause of nursing error (Keenan et al., 2013). (28) This result is consistent with literature that says that unsuccessful communication is one of the most prevalent causes of disastrous or sentinel occurrences in hospitals during handover. In addition, handover communication gaps and omissions might also lead to patient care mistakes (Tobianoet al., 2020; The Joint Commission, 2016; Steggers and Blaz, 2013). ${ }^{(2,11,25)}$

Concerning the views of some nurses on improving the current handover process, providing of honest accurate information in a structured standardized form and sufficient time and nursing personnel are crucial for enhancing the process of handover. These results may be due to the fact that time restrictions, interruptions, noise, and interpersonal tensions challenge handovers communication. The lack of a tool generated variability and spent more time for organizing the job. The implementation of a standard handover tool has consequently been given priority and has been shown to assist quick communication, to provide consistent guidance, and to create common mental models (Cornell et al., 2013; Halm, 2013; Holly and Poletick, 2014). $\left.{ }^{(29,} 30,31\right)$ Literature reports that data on handover is commonly incorrect, unsatisfied, partial or 
incomprehensible (Flemming and

Hubner, 2013; Holly and Poletick, 2014;

Pezzolesi et al., 2010; Rabøl et al., 2011;

Staggers \& Blaz, 2013; Welsh et al., 2010). (2, 31, 32, 33, 34, 35) $^{.}$

Regarding the level of agreement of nurses on the quality of the process of handover, the results show less than half of nurses viewed that the overall quality of handover process is of high level, especially for documentation, conduction process, surrounding and teamwork. These findings are congruent with the literatures which indicating that teamwork and cooperation are vital ideas because ED nurses and floor nurses must work together to address any gaps in the transition process and promote the building of teams and socialize new nurses (Ayala, 2017; Marutyan, 2016; Delrue, 2013; Staggers \& Blaz (2013). ${ }^{(2,}$ 8, 18, 36) ED environment and surroundings can affect handovers because it may be noisy and susceptible to interference (e.g. pagers, phone calls) and can be carried out under emotional and physical stress, which can result in errors and data losses during handover process (Marutyan, 2016; Delrue, 2013). ${ }^{(8,18)}$

Results also showed high statistical significant correlation between nurses' experiencing errors and level of handover process quality as well as statistical significant correlation between information provided during handover and total quality level of handover process. These results are agreed with Marutyan, $\mathbf{2 0 1 6}^{(\mathbf{8})}$ whoconcludedthata handover is largely dependent on the interpersonal skills of the caregiver as well as the knowledge, level of understanding and experience level of the caregiver. These findings also correspond with other studies which have shown that the nursing experience has an impact on the transfer of important patient information and on controlling time for the process of bedside handover. The more experience a nurse has as strength, the more accurate and responsible he or she is. Varying experiences between various nurses could also result in weaknesses, such as lack of understanding or difficulty in the communication of patient information (Evans et al., 2010, Pezzolesi et al., 2010; Eggins and Slade, 2016). ${ }^{(7,33,10)}$

\section{Conclusion}

Although the results of this study cannot be generalized, this study raised that handovers will continue to be challenging as the study demonstrates that nurses experienced error during the handover process owing to lack of communication, inadequate time to ask questions or clarify information and lack of standardization 
influencing patient care. Also, most of them were used and preferred with the inter-unit handover method written template and face-to-face handover, as well as being dissatisfied with the current handover process. The participants suggested that providing sufficient data and time is crucial for enhancing the process of handover.

\section{Recommendations}

Based on findings of the current study researchers recommend the following:

- Design nurses' standardized tools to optimize the quality of handover process according to ED context and each inpatient unit.

- Conduct training programs to help nurses to gain knowledge, develop competencies, and apply tools to manage the intricate nature of handover process, to enhance nurses' satisfaction with the process.

- Teach how to handover patients in formal didactic session in college of nursing.

- Adopt technology to facilitate and improve handover process by eliminating errors and providing easy access to information.

- Also, it is recommended to conduct further research involving multiple units and a larger number of participants and get agreements related to information that should be reported through handover process.

\section{Limitations}

Study limitations included a small sample size in one hospital and only one setting

\section{References}

1- Campbell D, Dontje K. Implementing Bedside Handoff in the Emergency Department: A Practice Improvement Project. Journal of Emergency Nursing. 2019; 45(2): 149-54

2- Staggers, N., and Blaz, J. W. Research on nursing handoffs for medical and surgical settings: An integrative review. Journal of Advanced Nursing. 2013; 69(2): 24762. https://doi.org/10.1111/j.13652648.2012.06087.x.

3- Suganandam DK. Handoff Communication: Hallmark of Nurses. Indian J Cont Nsg Edn. 2018; 19 (1): $12-20$ Available from: https://www.ijcne.org/text.asp?2 $018 / 19 / 1 / 12 / 286083$

4- Forde $M$ and Coffey A. Bedside handover at the change of nursing shift: A mixed-methods study. Journal of clinical Nursing. 2020; 29 (20): $3731-42$

5- Briones A. A. Admission Handover between emergency department and 
inpatient units. University of San Francisco. Master's Projects and Capstones. 2016.460

6- Abraham J., Kannampallil T. G., Almoosa K. F., Patel B., Patel V. L. . Comparative evaluation of the content and structure of communication using two Handover tools: implications for patient safety. Journal of critical care. 2014; 29(2): 311-e1.

7- Evans S. M., Murray A., Patrick I., Fitzgerald M., Smith S., Andrianopoulos N., Cameron P. Assessing clinical Handover between paramedics and the trauma team. Injury. 2010 ;41(5): 460-464.

8- Marutyan Y. Evaluation of the Nursing Handover Process from Emergency Department to In-Patient Unit.The University of San Francisco. Master's Projects and Capstones. 2016.

9- Raeisi A, Rarani MA, Soltani F. Challenges of patient handover process in healthcare services: A systematic review. J Edu Health Promot 2019; 8:173.

10-Eggins $S$ and Slade D. Communication in clinical handover: improving the safety and quality of the patient experience. Journal of Public
Health Research. 2016; 4 (666):197:9

DOI: $10.4081 /$ jphr.2015.666

11- The Joint Commission. 2016 National Patient Safety Goals presentation. 2016 . Retrieved from http://www.jointcommission. org/npsg_presentation.

12-Hilligoss B., Cohen M. D. The unappreciated challenges of betweenunit Handovers: negotiating and coordinating across boundaries. Annals of emergency medicine. 2013; 61(2): 155-60.

13- Benjamin M. F., Hargrave S., Nether K. .Using the Targeted Solutions Tool® to improve emergency department Handovers in a community hospital. The Joint Commission Journal on Quality and Patient Safety. 2016;42(3): 107-AP4.

14- Gunawan D, Hariyati R T and Fitri D. International Journal of Nursing and Health Services (IJNHS). 2018; 1(2): 75-82.

15-Scott P., Ross P., Prytherch D. Evidence-based inpatient Handovers: a literature review and research agenda. Clinical Governance: An International Journal, 2012;17(1): 1427. 
16-Stewart K . SBAR, communication, and patient safety: An integrated literature review .2016.

17- Lau F and Kuziemsky C . Handbook of eHealth Evaluation: An Evidencebased Approach. University of Victoria Publisher. British Columbia. Canada: 2016; 231-24

18-Delrue KS. An Evidence-Based Evaluation of the Nursing Handover Process for Emergency Department Admissions; 2013;1-122. Available from:

http://scholarworks.gvsu.edu/dissertati ons/10/

19- Hilligoss B., Cohen M. D. Hospital Handovers as multifunctional situated routines: implications for researchers and administrators. In Biennial Review of Health Care Management. Emerald Group Publishing Limited .2011.

\section{0- Carroll J. S., Williams M., Gallivan} T. M. The ins and outs of change of shift Handovers between nurses: a communication challenge. BMJ Qual Saf. 2012; 21(7): 586-593.

21-Jewell J. A. Standardization of inpatient Handover communication. Pediatrics. 2016; 138(5): e20162681 . doi: 10.1542/peds.2016-2681.
22- Rhudy L. M., Johnson M. R., Krecke C. A., Keigley D. S., Schnell S. J., Maxson P. M., Warfield K. T. Change of Shift Nursing Handoff Interruptions: Implications for Evidence Based Practice. Worldviews on Evidence- Based Nursing. 2019; 16(5), 362-370.

23-Birmingham P., Buffum M. D., Blegen M. A., Lyndon, A. Handovers and patient safety: grasping the story and painting a full picture. Western journal of nursing research. 2015;37(11): 1458-1478.

24- Young JQ, Wachter RM, Ten Cate O, et al Advancing the next generation of handover research and practice with cognitive load theory. BMJ Qual Saf . 2016; 25(2): 66-70.

25- Tobiano G., Ting C., Ryan C., Jenkinson K., Scott L., Marshall A. P. Front line nurses' perceptions of intra hospital handover. Journal of Clinical Nursing. $2020 ; 29(13-14)$ : 2231-8

26-Drach Zahavy A., Goldblatt H., Maizel A. Between standardisation and resilience: nurses' emergent risk management strategies during Handovers. Journal of clinical nursing. 2015;24(3-4):592-601. 
27- Nasarwanji M. F., Badir A., Gurses

A. P. Standardizing Handover communication. Journal of nursing care quality. 2016;31(3): 238-44 .

28- Keenan G., Yakel E., Dunn Lopez K., Tschannen D., Ford Y. B. Challenges to nurses' efforts of retrieving, documenting, and communicating patient care information. Journal of the American Medical Informatics Association. 2013;20(2): 245-251 .

29- Cornell P., Gervis M. T., Yates L., Vardaman J. M. Improving shift report focus and consistency with the situation, background, assessment, recommendation protocol. Journal of Nursing Administration. 2013;43(7/8): $422-8$.

30- Halm M. A. Nursing Handovers: Ensuring safe passage for patients. American Journal of Critical Care. 2013;22(2): 158-162 .

31- Holly C., Poletick E. B. A systematic review on the transfer of information during nurse transitions in care. Journal of clinical nursing. 2014;23(17-18): 2387-96.

32-Flemming D., Hübner U. How to improve change of shift Handovers and collaborative grounding and what role does the electronic patient record system play? Results of a systematic literature review. International journal of medical informatics. 2013;82(7): 580-92 .

33-Pezzolesi, C., Schifano, F., Pickles, J., Randell, W., Hussain, Z., Muir, H., \& Dhillon, S. Clinical Handover incident reporting in one UK general hospital. International Journal for Quality in Health Care. 2010;. 22(5): 396-401

34- Rabøl L. I., Andersen M. L., Østergaard D., Bjørn B., Lilja B., Mogensen T. Descriptions of verbal communication errors between staff. An analysis of 84 root cause analysisreports from Danish hospitals. BMJ quality \& safety. 2011; 20(3): 268274 .

35- Welsh C. A., Flanagan M. E., Ebright P.. Barriers and facilitators to nursing Handovers: Recommendations for redesign. Nursing outlook. 2010;58(3): $148-54$ DOI: 10.1016/j.outlook.2009.10.005

36-Ayala W. L. Impact of a Standardized Tool on Handover Quality in Nurse Change-of-Shift Reports .2017. 